\title{
Tiotropium Respimat increases the risk of mortality: con
}

\author{
Eric D. Bateman
}

Affiliations: Dept of Medicine, University of Cape Town, Cape Town, South Africa.

Correspondence: E.D. Bateman, University of Cape Town Lung Institute, George Street, Mowbray 7700, Cape Town, South Africa. E-mail: eric.batemanquuct.ac.za

0 @ERSpublications

Conclusions on cardiovascular risk associated with tiotropium Respimat in COPD must await results of appropriately designed studies http://ow.ly/mAoBD

The introduction of the once-daily inhaled anticholinergic, tiotropium, administered via the HandiHaler dry-powder device, signalled a new era in the management of chronic obstructive pulmonary disease (COPD). The unquestionable benefit that it provides for patients has made it a market leader for this indication; improved lung function, exercise capacity and health status and reduce exacerbation frequency [1-3]. In the large 4-year UPLIFT (Understanding Potential Long-Term Impacts on Function with Tiotropium) study, tiotropium therapy was also associated with reduced all-cause mortality $[1,4]$. In response to this success and to improve the ease of use, particularly in elderly patients with limited dexterity, Boehringer Ingelheim embarked on the development of the Respimat Soft Mist Inhaler (SMI) that, at a dose of $5 \mu \mathrm{g}$ tiotropium, provides non-inferior spirometric improvement to the $18 \mu \mathrm{g}$ tiotropium HandiHaler dose $[5,6]$, and in studies, of up to 12 months, shows similar improvements in other endpoints including a reduced risk of COPD exacerbations [7, 8]. However, an unexpected finding, in three Respimat studies, was an imbalance in the risk of death, which on closer scrutiny appeared to occur in patients with cardiovascular disease and, in particular, a history of arrhythmias $[7,8]$. In response to this safety concern the manufacturer, Boehringer Ingelheim, in consultation with regulatory authorities [9], first embarked on a large study (17 000 participants) known as TIOSPIR (the Tiotropium Safety and Performance in Respimat Trial) (ClinicalTrial.gov reference NCT01126437), powered to examine for an imbalance in mortality [10]. Secondly they setup an additional pharmacokinetic study, which compared systemic exposures from the HandiHaler and the Respimat SMI [11]. In spite of these actions, some contend that there is already sufficient evidence that tiotropium Respimat SMI increases the risk of death in patients with COPD for it to be withdrawn globally $[12,13]$. The counter view, that I will defend, is first that while acknowledging evidence of cardiovascular risk with anticholinergic use in patients with cardiac disease, the evidence from clinical trials that the Respimat SMI device increases the risk of mortality is inconclusive. Secondly, that the mechanism proposed for this alleged increased risk of mortality is speculative and not supported by fact. Further, that it is reasonable to await results of studies designed to address concerns. Finally, that the appropriate response to a safety concern for a drug with a generally highly satisfactory efficacy and safety record, is to identify the "at risk" population and ensure that prescribers are aware of and avoid its use in such patients. The premature withdrawal of the Respimat SMI will set back research in the field of anticholinergics for airways diseases (e.g. in asthma and bronchiectasis) and limit gains in understanding the therapeutic potential for this class of drug.

Concern about the safety of anticholinergics in patients in high-risk categories of heart disease is not new or confined to tiotropium and the Respimat SMI delivery device [14-18] The "pro-arrhythmic" and "proischaemic" effects of anticholinergics are adequately discussed in a recent opinion paper by VAN DEN BRUEL et al. [16]. However, in spite of this evidence the favourable risk-benefit ratio of anticholinergics has ensured

Received: March 082013 | Accepted after revision: April 112013

Conflict of interest: Disclosures can be found alongside the online version of this article at www.erj.ersjournals.com

Copyright @ERS 2013 
their continued use in COPD, supported by analysis like that of KESTEN et al. [19] of 29 trials with tiotropium and the UPLIFT study, in which all deaths were carefully adjudicated [1]. Tiotropium treatment was not associated with increased risk of death from myocardial events or strokes [1]. This conclusion was supported by the Federal Drug Agency (FDA), on whose behalf Michele et al. [9] wisely commented "We have entered an era of increasingly frequent publication of meta-analyses, some of which identify potential safety signals. Such publication commonly leads to urgent calls to take immediate regulatory action, without acknowledgment of potential pitfalls in the interpretation of data from meta-analyses and pooled analyses, such as those encountered in the tiotropium evaluation. We must use measured restraint during our evaluations to ensure that safe drugs remain on the market and that their use is not restricted in a way that unnecessarily denies beneficial interventions to patients who need them. The continuing evaluation of potential safety signals at the FDA requires assessment of all available data from many sources, with the goal of reaching sound conclusions in a manner that is transparent to physicians and patients". In addition to this it could be added that repeated analyses of the same limited data, even if with improved methods, does not improve insights [20]. However, the FDA acknowledged that the concern surrounding the Respimat SMI formulation is unresolved and requires further examination [9]. Specific concerns, common to all trials with tiotropium are that the true risk may have been masked by methodology issues; namely, recording sudden deaths as general deaths, the use of composite scores for stroke and myocardial events, and exclusion from trials of patients with unstable arrhythmias, a history of heart failure or heart attack within the previous 6 months, used in all tiotropium trials sponsored by Boehringer Ingelheim [18, 21].

But the current debate concerns the tiotropium Respimat SMI and not the safety of tiotropium in general, presumably because the HandiHaler formulation is considered to be safe, and withdrawal unjustified. Thus the comparison of safety (or harm) should be between the tiotropium Respimat SMI and tiotropium HandiHaler. Yet the trials that gave rise to the concern compared tiotropium Respimat SMI not with the HandiHaler, but with a placebo. Only the TIOSPIR study addresses this question [10]. However, it is appropriate to examine the evidence upon which the concerns are based. The meta-analysis reported by SINGH et al. [18], from which a combined mortality estimate for all-cause mortality versus placebo of 1.46 (95\% CI $1.01-2.10 ; \mathrm{p}=0.04, \mathrm{I}^{2}=24 \%$ ) is reported, has several limitations. First, only five of the six available placebocontrolled studies were included, and the conclusions were driven by three 1-year studies in which there was a mortality imbalance [7, 8]. Notably they did not include the sixth study (BI1201.14 ClinicalTrials.gov reference NCT00528996), which was a 6-month study of more than 850 patients in which there were only two deaths in the tiotropium Respimat SMI arm and five in the placebo arm of the study [22]. Secondly, there were errors in assignment of deaths to treatment groups (BI205.251 and BI205.2522) which, when included, reduce the calculated risk. Thirdly, is the problem of the differential dropout of patients from the placebo group. In addition, in one of the two studies in which an imbalance was observed, the mortality rate in the placebo arm was unusually low $(0.77 \%)$, compared with placebo-treated patients in other studies, which characteristically ranges from $1.5 \%$ to $2.5 \%$ or even higher [8]. Lack of consistency of results is not unusual in clinical trials, even in twin studies, without apparent reason. This is a plausible explanation for the imbalance in the tiotropium Respimat SMI trial results. Given these uncertainties, and particularly the absence of a head-tohead comparison of tiotropium administered in equivalent doses from the two devices, the appropriate response was to perform such a study, adequately powered to examine mortality and to await the results before concluding greater risk with the Respimat SMI device. Results from the TIOSPIR study, which examines two doses of tiotropium Respimat SMI $(2.5 \mu \mathrm{g}$ and $5 \mu \mathrm{g}$ daily $)$, are expected later this year.

A second concern about the Respimat SMI is the presumption, based on limited information, that systemic exposure to tiotropium is greatly increased with this device. Hence, owing to its delivery as a fine mist, patients might be exposed to "higher peak concentrations and overall exposure, providing a plausible mechanism of differential toxicity" [18]. The paucity of published pharmacokinetic information on the Respimat SMI formulation is presumably attributable to the fact that tiotropium was well established in the treatment of COPD and had a satisfactory safety record, with a wide therapeutic window. Thus, the main requirement was to ensure clinical equivalence based on lung function. Several doses $(1.25,2.5,5$ and $10 \mu \mathrm{g}$ once daily) were evaluated. SINGH et al. [18] and others base their opinion on twin efficacy studies (BI205249 and BI205.250), in which pharmacokinetics (PK) was performed on a non-random subgroup with limited time-points, the earliest of which was at 10 min post dose $[5,17,18]$. On day 29, 10 min and hourly up to $6 \mathrm{~h}$, the geometric mean plasma concentration in the pre-specified pooled analysis of these studies were marginally higher with the tiotropium Respimat SMI $5 \mu \mathrm{g}$ than with the HandiHaler $18 \mu \mathrm{g}$ dose (10 min geometric mean peak values $11.5 \mathrm{pg} \cdot \mathrm{mL}^{-1}$ versus $8.5 \mathrm{pg} \cdot \mathrm{mL}^{-1}$, respectively) and only the $10 \mu \mathrm{g}$ Respimat SMI dose resulted in higher peak values. The former difference is less significant in the light of considerable inter-subject variation in the studies, which was similar in both groups. The range of systemic exposure, for the two devices, was within the margins of equivalence [5]. In a second study of similar design, 10 -min peak values at steady state for the two devices was also therapeutically equivalent (geometric mean 
tiotropium plasma concentrations of $94.4 \mathrm{pg} \cdot \mathrm{mL}^{-1}$ and $89.6 \mathrm{pg} \cdot \mathrm{mL}^{-1}$ for the $5 \mu \mathrm{g}$ Respimat SMI and $18 \mu \mathrm{g}$ HandiHaler, respectively) [6].

However, the most relevant evidence comes from the recently conducted PK study with a randomised, placebo- and active-controlled, double-blind, five-way crossover design (BI205.458, ClinicalTrial.gov reference NCT1222533), which is the first to compare three doses of tiotropium Respimat SMI (1.25, 2.5 and $5 \mu \mathrm{g}$ or placebo) with the $18 \mu \mathrm{g}$ HandiHaler. 154 patients with COPD were randomised [11]. The primary outcome measures were maximum plasma concentration of tiotropium at steady state (ss) at 4 weeks and safety monitoring included Holter ECGs. To ensure an adequate readout of plasma levels, samples were collected at $-5,2,5,7,9,12,15,30,40$ and $60 \mathrm{~min}$ and at 2, 4 and $6 \mathrm{~h}$ post dose. The results, which have not been published but reported on ClinicalTrials.gov [11], appear to confirm dose-ordering of plasma tiotropium from the three Respimat SMI doses. Significantly, the bioavailability with Respimat SMI $5 \mu \mathrm{g}$ was lower than the HandiHaler $18 \mu \mathrm{g}$. The geometric mean ratio of test to reference (Respimat SMI $5 \mu \mathrm{g}$ to HandiHaler $18 \mu \mathrm{g}$ ) was $81 \%$ (90\% CI $73-89 \%)$ for Cmax,ss and 76\% (90\% CI 70-82\%) for AUC0-6,ss. Importantly the median time to maximum plasma level was 5-7 min for both devices (all doses) and the variability of PK parameters were similar [11]. These results are reassuring and do not support the hypothesis that the Respimat SMI results in earlier systemic exposure to tiotropium after dosing.

A principle of therapeutics is to identify patients groups who stand to benefit from a treatment and in whom risks are minimal and acceptable. Undue criticism has been directed at the design of studies with tiotropium (both formulations), including the TIOSPIR study, where patients likely to be at highest risk were excluded; patients with renal disease (in whom impaired tiotropium elimination might lead to higher plasma levels), patients with "unstable" arrhythmias, cardiac failure or a recent myocardial infarction [13, $20,21]$. It is pointed out that COPD patients are elderly and many have cardiac and other comorbidities, and implied that excluding them will provide a false conclusion about the safety of tiotropium. However, it is standard practice in clinical efficacy trials to exclude patients whose comorbidities may interfere with the assessment of benefit. Special high-risk categories of patient are best studied in separate suitably designed and powered trials. More often, such patients are excluded and registration cautions against their use in categories of patients not included. It should be noted that cardiac disease in general, and medication use for cardiovascular disease, were not exclusion criteria in the tiotropium studies, and that, with the exception of pre-existing rhythm disorders in the retrospective subgroup analyses of the Respimat SMI studies, patients with cardiac disease have not been shown to be at increased risk [1]. It was appropriate that the TIOSPIR study employed the same exclusion criteria as previous trials, as the study question was not the general safety of tiotropium in high risk patients but whether the Respimat SMI formulation is as safe as the HandiHaler for the indications and patients for whom the HandiHaler is prescribed.

A further argument advanced for the withdrawal of the Respimat SMI device is on the basis of need. Do we need the tiotropium Respimat SMI? It is true that the record of the Handihaler for delivering tiotropium as a powder is good, in spite of its rather simple design and formulation. Further, designing a study to differentiate the benefits of one inhaler device from another is very challenging. However, few clinicians doubt that preference is associated with adherence, some patients have difficulty with devices requiring dexterity and powder formulations are poorly tolerated by some. It is inconsistent to call for withdrawal of a device on the basis of safety based on slender grounds when there are several more potentially dangerous inhalational methods in use in the same patient group in the form of jet and ultrasonic nebulisers and other delivery devices administering doses that are generally both high and impossible to standardise and have similar potential to deliver anticholinergics into peripheral airways.

In summary, the call to withdraw tiotropium Respimat SMI worldwide errs on the side of caution as there is considerable doubt surrounding the primary concern that tiotropium Respimat SMI device is more dangerous than the HandiHaler in doses of equivalent efficacy. Secondly, because the putative mechanism for the apparent increased mortality with the Respimat SMI is not supported by PK data, and there is no other plausible reason for increased risk. Thirdly, that the safety concerns highlighted by the Respimat SMI trials are neither new nor different from those already identified for this class of drug in COPD, and are better addressed by reminding prescribers that anticholinergics, like several other classes of drug, should be used with circumspection in patients at high risk of arrhythmias, unstable cardiac disease, and in renal failure. It is suggested that the attention given to the Respimat SMI data in the form of reviews based on the same limited data, editorials and calls for banning, is unfortunate, particularly when within months, the results of studies designed to address the major issues, will be available. While the safety of patients remains paramount, and history does not reward complacency and indecision, decisions must be evidence-based and balanced and serve the wider good of the patients that we serve.

\section{References}

Tashkin DP, Celli B, Senn S, et al. A 4-year trial of tiotropium in chronic obstructive pulmonary disease. $N$ Eng $J$ Med 2008; 359: 1543-1554. 
2 O'Donnell DE, Flüge T, Gerken F, et al. Effects of tiotropium on lung hyperinflation, dyspnoea and exercise tolerance in COPD. Eur Respir J 2004; 23: 832-840.

3 Maltais F, Hamilton A, Marciniuk D, et al. Improvements in symptom-limited exercise performance over $8 \mathrm{~h}$ with once-daily tiotropium in patients with COPD. Chest 2005; 128: 1168-1178.

4 Celli B, Decramer M, Kesten S, et al. Mortality in the 4-year trial of tiotropium (UPLIFT) in patients with chronic obstructive pulmonary disease. Am J Respir Crit Care Med 2009; 180: 948-955.

5 Van Noord JA, Cornelissen PJG, Aumann JL, et al. The efficacy of tiotropium administered via Respimat Soft Mis Inhaler or HandHaler in COPD patients. Respir Med 2009; 103: 22-29.

$6 \quad$ Ichinose M, Fujimoto T, Fukuchi Y. Tiotropium $5 \mu \mathrm{g}$ via Respimat and $18 \mu \mathrm{g}$ via HandiHaler ; efficacy and safety in Japanese COPD patients. Respir Med 2010; 104: 228-236.

7 Bateman ED, Singh D, Smith D, et al. Efficacy and safety of tiotropium Respimat SMI in COPD in two 1-year randomized studies. Int J Chron Obstruct Pulmon Dis 2010; 5: 197-208.

8 Bateman ED, Tashkin D, Siafakas N, et al. A one-year trial of tiotropium Respimat ${ }^{\circledR}$ plus usual therapy in COPD patients. Respir Med 2010; 104: 1460-1472.

9 Michele TM, Pinheiro S, Iyasu S. The safety of tiotropium - the FDA's conclusions. N Engl J Med 2010; 363: 1097-1099.

10 ClinicalTrials.gov. Comparison of Tiotropium in the HandiHaler versus the Respimat in Chronic Obstructive Pulmonary Disease. http://www.clinicaltrials.gov/ct2/show/study/NCT01126437

11 US National Institutes of Health. ClinicalTrials.gov. Tiotropium Respimat pharmacokinetic study in COPD. 2010 www.clinicaltrials.gov/ct2/show/results/NCT01222533

12 Ram FS. Spiriva (Respimat) increases mortality by 52\% in patients with COPD: time to take action. $N Z$ Med J 2011; 124: 117-118.

13 Beasley R, Singh S, Loke YK, et al. Call for worldwide withdrawal of tiotropium Respimat mist inhaler. BMJ 2012; 345: e7390.

14 Peters NL. Snipping the thread of life. Antimuscarinic side effects of medications in the elderly. Arch Int Med 1989; 149: 2414-2420.

15 Singh S, Loke YK, Furberg CD. Inhaled anticholinergics and risk of major adverse cardiovascular events in patients with chronic obstructive pulmonary disease: a systematic review and meta-analysis. JAMA 2008; 300: 1439-1450.

16 Van den Bruel A, Gailly J, Neyt M. Does tiotropium lower exacerbation and hospitalization frequency in COPD patients: results of a meta-analysis. BMC Pulm Med 2010; 10: 50

17 Singh S, Loke YK, Enright P, et al. Pro-arrhythmic and pro-ischaemic effects of inhaled anticholinergic medications. Thorax 2013; 68: 114-116.

18 Singh S, Loke YK, Enright PL, et al. Mortality associated with tiotropium mist inhaler in patients with chronic obstructive pulmonary disease: systematic review and meta-analysis of randomized controlled trials. BMJ 2011; 342: d3215.

19 Kesten S, Jara M, Wentworth C. Pooled clinical trial analysis of tiotropium safety. Chest 2006; 130: 1695-1703.

20 Dong YH, Lin HH, Shau WY, et al. Comparative safety of inhaled medication in patients with chronic obstructive pulmonary disease: systematic review and mixed treatment comparison meta-analysis of randomised controlled trials. Thorax 2013; 68: 48-56.

21 Jenkins CR, Beasley R. Tiotropium Respimat increases risk of mortality. Thorax 2013; 68: 5-7.

22 Abrahams R, Moroni-Zentgraf P, Ramsdell J, et al. Safety and efficacy of the once-daily anticholinergic BEA2180 compared to tiotropium in patients with COPD. Respir Med 2013; 107: 854-862. 